
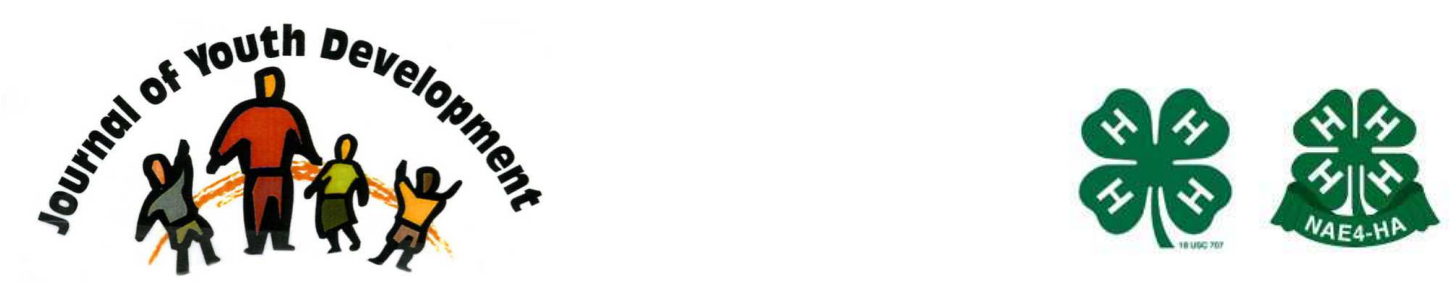

Bridging Research \& Practice

\title{
Youth Perspectives on Meaningful Participation in Community Based Programs: A Qualitative Assessment
}

Sherer W. Royce

School of Health, Kinesiology and Sport Studies

Coastal Carolina University

Conway, SC

sroyce@coastal.edu 


\title{
JOURNAL OF YOUTH DEVELOPMENT \\ bridging research and practice

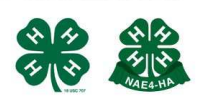

Volume 4, Number 4, Winter 2009

Article 090404FA006

\section{Youth Perspectives on Meaningful Participation in Community Based Programs: A Qualitative Assessment}

\author{
Sherer W. Royce \\ Coastal Carolina University
}

\begin{abstract}
Allowing the voiceless to have a voice is a tenet of empowerment. This paper highlights research that employed a participatory action research framework to gain a better understanding of young people's perceptions about youth empowerment and acquire their perspective (voice) about the meaningfulness of participation in out-of-school advocacy and volunteer program activities. Using Photovoice, the research provides a missing point of view in youth empowerment model development. Results indicate that the quality of a youth's participation in a community-based program is determined by 1) youth expressing themselves without censorship, 2) occasions for youth to expand their social networks with youth and adults, and 3) adults observing and valuing youth contributions. These findings raise implications for community-based, youth empowerment programs including program philosophy, program procedures, youth empowerment content and activities, and adult leadership style. The findings may assist practitioners when designing youth empowering activities and researchers when operationalizing youth empowerment.
\end{abstract}

\section{Introduction}

Youth today are typically characterized by adolescent risk taking behaviors and are frequently considered problems, community liabilities, and recipients rather than resources (Lerner \& Galambos, 1998). Adults rarely value today's youth as contributing members of society, therefore, opportunities for youth to participate in constructive adult behaviors or serve in productive citizenship roles are often scarce (Bales, 2001; Lerner \& Galambos, 1998). Without genuine opportunities to model productive adult-like behavior, youth do not gain developmental experience and may seek legitimacy in the participation of risk-taking behaviors such as alcohol, tobacco and other drug use, early sexual initiation, unprotected sex, crime, and violence ( 
Hawkins, 1998; Hawkins, Catalano, \& Miller, 1992). Youth programs have the potential of countering youth risk taking behaviors by constructing opportunities to teach the fundamental principles and skills needed to help young people become responsible, empowered, and productive citizens. But are programs meeting that charge?

\section{Purpose}

The evaluation of youth programs has historically relied on the analysis of participation levels and youth satisfaction including interactions with staff and enthusiasm for activities (Linquanti, 1992). Evaluations that merely take stock of program participation levels and satisfaction ratings (program status factors) provide little understanding of program processes and the links those processes have to youth development (Oden, 1995). It is important that programs realize that having youth participate is not the sole antidote for social problems because youth participation in programs is not always the same experience for each youth nor is it always meaningful in ways that may ultimately protect the youth. Therefore, research that quantifies the number of hours spent participating is misrepresenting what is truly protective for the "atrisk" youth (Astroth, 1997).

Oden (1995) contends that in order for research to support youth development, studies are needed to identify key factors that could be built into youth programs. An examination of the quality and not just the quantity of youth participation experiences is therefore critical. To understand quality of an experience is to understand what was meaningful about that experience for the youth as determined by the youth. When researchers understand what a meaningful experience is for a youth, then models can be developed to guide programs.

A critique of youth empowerment models (Chinman \& Linney, 1998; Kim, Crutchfield, Williams, \& Hepler, 1998; Zimmerman, 2000) reveals that they are theoretical and based on researchers conceptualization and do not articulate how youth perceptions about empowerment were incorporated into model development. Therefore, the purpose of this research was to gain a better understanding of young people's perception about youth empowerment and acquire their perspective about the meaningfulness of participation in out-of-school youth development and empowerment program activities.

This research utilized a participatory action research process whereby the community of interest determines relevant and effective solutions to problems that affect quality of life (George, Daniel, \& Green, 1999; Minkler \& Wallerstein, 2003; Stringer, 1999). The study was part of a statewide, community-based research project called the South Carolina American Legacy Empowerment (SCALE) Evaluation Project funded by the American Legacy Foundation with support from the Centers for Disease Control Foundation. South Carolina youth participating in out-of-school youth programs were involved in the research as researchers themselves. They provided the very integral yet missing youth voice in youth empowerment model development by examining ways the community and youth programs can provide meaningful experiences for youth participating in volunteer and advocacy projects.

\section{Research Methods}

\section{Study Population}

Purposeful sampling determined the selection of the SCALE study population. The particular programs in this evaluation study were selected based on a strict criteria of being an out-ofschool, community-based program, as well as one which considers itself a youth development 
and empowerment organization and/or having a tobacco use prevention mission. It was important to have project participants representing geographic, racial, gender and socioeconomic diversity. The two youth programs selected to participate in the research included Action Against Tobacco and Youth Service.

Action Against Tobacco is a youth tobacco prevention advocacy organization located in the largest metropolitan area in South Carolina. The mission of Action Against Tobacco is to advocate against teen tobacco use by developing strategies similar to those which the nationally recognized anti-tobacco campaign, the truth $\mathbb{R}$, promotes which also champions the use of empowerment as its approach to addressing issues.

Youth Service is a county-wide youth volunteer service organization located in a rural part of South Carolina with a participant roster of more than 500 youth. Youth Service is premised on youth development and youth empowerment principles and seeks to provide youth with tools necessary for success: access to a caring adult, a safe place, health education, marketable skills and opportunities to serve. The Youth Service mission is to instill an ethic of service among the rural county youth through cooperative community volunteer activities.

Twenty youth ranging in age from 13-20 years completed all phases of this qualitative evaluation research. The youth leaders of each organization were selected to participate in the study. The sample size for this qualitative study was kept intentionally small due to the volume of photographic data Photovoice would generate. However, these adolescents represented twelve schools (six middle schools and six high schools) in two distinct regions of South Carolina; one in a rural community located on the coast and the other in a large urban city on the other side of the state. Thirty percent of the participants were male $(n=6)$ and seventy percent were female $(n=14)$. Forty percent $(n=8)$ self identified as Caucasian, fifty-five percent $(n=11)$ African American, and five percent $(n=1)$ Asian.

\section{Data Collection}

Data collection observed an empowering and participative approach and used Photovoice, developed by Wang and Burris (1997), as a methodology for gathering the evidence of youth empowerment. The premise of the Photovoice methodology is "empowering communities through documentary photography." It is a specific photographic technique that puts cameras in the hands of people who don't have a voice; they have little power themselves, or little access to those who have power over their lives. The camera therefore becomes their tool, their voice. Photovoice can be seen as a grassroots approach to social action. That is, it is a process that can reach, inform and organize community members for social change (Wang \& Burris, 1997). Royce, Parra-Medina \& Messias (2006) have documented lessons learned from using Photovoice to examine youth empowerment in community-based programs.

During this Photovoice project, data was collected

1) from observations of the youth during their youth program meetings,

2) through the youth's photography and photo essays, and

3) from discussions/debriefings with the youth Photovoice teams after the youth compiled their photo essays including a large focus group of all team members.

During the debriefings, the self-selected teams (consisting of two to four youth researchers each) were guided in a discussion about their photo essays and overall findings of youth empowerment. The debriefings lasted approximately an hour and a half and were tape recorded. The focus group was conducted after all team debriefings had been completed and 
used a more focused discussion guide probing on points that were raised during the team debriefings. This session was also tape recorded and transcribed for analysis For more information about conducting Photovoice, visit www.photovoice.com (Wang, 2005).

\section{Data Analysis}

The data for analysis included the photo essays and their captions ( $n=8)$, transcriptions of the debriefings from each Photovoice team representing Action Against Tobacco $(n=2)$ and Youth Service $(n=6)$, transcriptions of a focus group summary discussion $(n=1)$, and observation notes taken of youth interactions during regular meeting sessions.

Data was analyzed using grounded theory techniques in order to operationalize and define youth perceptions of youth empowerment. To help build grounded theory, Glaser and Strauss advocate a constant comparison method of combining coding with analysis (Glaser \& Strauss, 1967). In the constant comparison method, the data is coded to generate categories and hypotheses. This method involves

- identifying, reducing, coding, and displaying categories of text data;

- analyzing the categories by comparing them to one another and checking for emerging themes;

- further refining the categories to focus on the details of empowerment and youth participation in the community and in youth programs; and finally,

- describing and summarizing the major themes.

The constant comparison method of analysis was used to analyze all transcript data associated with the Photovoice research project. NVIVO computer software was used to manage the coding processes and generate reports of all the associated categorical data.

Three levels of coding were used to create the themes and results of this research. The first step involved identifying passages of data related to outcomes of youth participation in community-based programs. The second level of coding was to separate the coded "outcomes of youth participation" passages into categories of supporting processes and constraining processes. The third level of coding identified influencing factors on the "supporting and constraining processes" such as program processes, adult program leaders, program philosophy, program social environment, program structure, youth and peers, individuals, church, community institutions, media, schools and Photovoice project in programs.

\section{Results}

Regarding youths' perspectives on youth development and empowerment programs, three themes emerged from the data that illustrate dimensions of meaningful participation. The themes describe the context and environment by which youth development and empowerment programs could meaningfully engage youth:

1) Youth Expression without Censorship,

2) Expanding Social Networks with Youth and Adults

3) Observing and Valuing Youth Contributions.

\section{Theme 1: Youth Expression without Censorship}

The ability to be expressive and having a voice was a prominent theme that emerged from the youth data. Youth want to be able to express themselves and have a voice, yet they are very 
self-conscious and cautious about doing so. They defined their voice as communicating, speaking out and providing one's opinion, demonstrating skills, expressing creativity, and decision-making. While the youth believed that they have many ways to express themselves, it was felt that they do not always have an audience willing to engage or listen to them.

Barriers youth identified which might inhibit them from gaining voice and censor their expression are

(a) the prevailing negative images adults have of youth,

(b) the fear of saying something wrong,

(c) an omnipresent and overly watchful adult leader,

(d) unconstructive criticism from adults, and

(e) and adult-dominated decision-making and control.

\section{A. The prevailing negative images adults have of youth.}

Youth unanimously agreed that a negative stereotype of teens exists, "There's the good and there's the bad and people tend to see the bad." While many young people have "a lot of good stuff to say" to adults, they fear that adults and program leaders do not take them seriously. For instance, one youth fretted, "A lot of times, people see that you are a teenager...and that because you are teenager, even if you have a good idea you couldn't have come up with this because, you know, you're only a teenager. You're only in high school. What do you know?" Therefore, adult program leaders can be part of the problem and inhibit youth empowerment through expression when they do not recognize the positive side of youth.

\section{B. The fear of saying something wrong.}

Potential criticism and scrutiny from a youth's audience is a barrier to expression. While discussing youth speaking out on an issue or simply asking a question in front of a group of peers or adults, several youth reported that "fear of being put down while speaking one's mind" or the potential of "getting in trouble" inhibits youth expression and communication. Therefore, the youth felt that when they express themselves they are taking a risk. Youth suggested, "To have voice, you have to be prepared for rejection and criticism. And you have to prepare for it all. You puttin' yourself under scrutiny cause whatever you say, somebody's going to take it apart to see if there's any flaws in it."

\section{An omnipresent and overly watchful program leader.}

When program leaders subscribe to the prevailing sentiment that youth are liabilities and problems, they may not listen to the youth or provide youth the freedom to experiment and take risks. Instead, they may be looking for youth mistakes. These actions may inhibit a youth's desire to participate altogether. As one youth relayed an experience she had, "...It's just that you don't want somebody always on your back trying to make sure you're not going to do anything bad. You want people to actually watch you for the things that you do good."

\section{Unconstructive criticism from adults.}

Program leaders can offset censorship and facilitate youth efficacy for expression by providing reasoning to the youth. For example, one youth explained how a program leader provided constructive criticism about the potential for the success of a youth's program idea with an explanation about why a project could not be achieved. "...And we went to them with an idea. And then, if it was feasible, they said, 'OK.' If it wasn't then they said, 'Well, we wouldn't be able to do that.' And they told us the reason why 


\section{E. Adult-dominated decision-making and control.}

Some youth groups have a philosophy of being youth run. That is, youth are given more responsibility (voice) in a program beyond being passive recipients of services or participants in projects. They may participate as a youth representative on an adult-filled board of directors or vote on adult-initiated ideas. Many of the youth commented that they had been consulted by the adult leaders on decisions important to their program. However, the ultimate decisions were mostly made by the adults. The youth concurred that their consultations seemed like token gestures at best without the adults truly listening or considering their ideas.

Having been told repeatedly that theirs was a youth run organization and given a project to accomplish, one youth expressed his frustrations in these words: "That was the meeting that really hit me that it was not a youth movement; whenever we knew it was more adults than youth voting on it (project plan). If you call it a youth-led group, then have the youth lead it. And, adults can get their influence, but you have to keep adults from trying to take it over." Therefore, youth should not be led to believe that they are in charge then have their leadership stripped from them. Another youth commented, "We can understand that there are some things that youth can't do that adults can. We understand that. We want the adult support, but if you want youth to run the group, then youth should run the group."

Furthermore, the first youth added, "Youth don't work like the adults want them to work." Therefore, youth may appear to the adults that they are not taking the project seriously. This, too, could potentially result in adults resuming control of the decision-making for program activities when they do not see the results that they wish to have.

\section{Theme 2: Expanding Social Networks with Youth and Adults}

Community programs have the capability of expanding a youth's network of friends and acquaintances. Community youth programs provide places for youth to gather and "hang outside the home," to have fun, and to express themselves. They are places that may provide service opportunities and other projects for youth to plan, implement or just participate. Community programs are also places that provide youth opportunities for social action or to join a "cause." Youth characterized community programs as agents for expanding and strengthening social networks by:

(a) promoting diversity (age, race, schools, gender),

(b) providing a singular common goal,

(c) forging group identity and teamwork, and

(d) fostering positive relationships with adult leaders.

\section{A. Opportunities for diversity.}

Community venues and programs are potential catalysts for youth development and empowerment. Having a place to go with friends in the community to have fun encourages youth to better their own skills and learn new ones. Refine. Additionally, youth believe that they have empowerment when with their peers and therefore, they can learn from each other.

\section{B. Providing a singular common goal.}

Youth in both programs believed that providing a singular, common program goal is a way to have diverse youth network together. For instance, "We all get along and we are all from different schools and we just clash all together because we all want to volunteer. We all have that in common," one youth noted, "Youth Service is a good way to get people who don't think 
that they have anything in common to work with each other and to realize that they're not that different, you know, they maybe have racial differences and cultural differences, but it just helps people to work together that normally wouldn't and so I think it's a good thing."

\section{Forging group identity and teamwork.} Both, Youth Service and Action Against Tobacco offer youth the possibility of expanding their social networks by coming together as a team for a common purpose (volunteer service) or social action cause (tobacco prevention) and developing group identity around a common goal.

According to a concurring group of youth Photovoice participants, schools are not places where youth diversify their social networks. Students tend to go through school with their same cliques of similar youth. Therefore, it was believed that schools are not venues that build diversity within groups. Youth agreed, "In schools, you don't tend to accept anyone other, you know, that's different." One youth reflected on her experience with diversity interactions, "When we do things, you have to force 'em together. You gotta put 'em in the environment that makes them have to discuss with each other. Make them have to talk with each other."

D. Fostering positive relationships with adults. Community programs are places for youth to build relationships with adults. The Photovoice youth revealed, however, that it is difficult to cultivate these friendships because most often, adults wear an authoritative hat in their role as program leader. That authority inherently creates a "power over" dynamic that can be awkward for youth to breach. As well, youth often do not possess the confidence or skills to eliminate that barrier or simply do not realize that it is acceptable to develop friendships with adult authority figures.

Adult program leaders can soften the power gap and attempt to level the playing field by the manner in which they communicate with and listen to the youth. The youth respondents indicated positive adult communication and interactions will have an overall greater impact on the youth's experience in the program. This requires adults trusting youth, adults showing care for youth, and adults serving as friends. Several youth suggested that adults and program leaders who are effective communicators with youth are those who are easy to approach and who spend time getting to know you. One youth positively remarked about his program's adult leadership, "They don't talk to you like you're a teenager. They talk to you like you're a human being. They appreciate what you're doing. And that's really important."

Two youth offered these comments about positive adult leader relationships, "They're (program leaders) so welcoming. They're just so easy to approach and talk to. And even if you just need someone to talk to about anything, you can just go to'em. It's kind of like a friend more than an adult."

The youth also identified certain communication characteristics that hinder the development of good adult relationships with them. These include adults using big words, ordering youth around, jumping to conclusions and prejudging youth.

\section{Theme 3: Observing and Valuing Youth Contributions in the Community and Youth Program}

Youth want to have influence and make a positive impact in their community as well as their youth program. Youth defined this dimension of meaningful participation as

(a) receiving positive feedback and validation from others, 
(b) having a positive impact on others, and

(c) contributing to the success of their program.

Supporting factors included smiles, verbal recognition, being listened to by adults, and participating in a program's processes.

A. Receiving positive feedback and validation from others. Volunteering in the community and participating in advocacy projects are ways youth can find opportunities to contribute and be valued. Many feel, however, they do good things that often go unnoticed. "There's a whole lot of good that's happening throughout the state that youth have done. But you tend to...don't' hear about that," said a youth participant. Therefore, youth feel that they need an organization to back them up and support their good deeds.

Youth want to be valued as a contributor. Recognition, positive feedback and validation from community members for their good deeds and efforts of being part of the solution is one reward youth find inspiring. Verbal feedback or even a smile from those who youth assist in the community or in a program itself can have a strong motivating influence on a young person to continue serving. One Youth Service participant explained her feelings from serving in the community, "When you help 'em out and you get to see what you've done for them and just the look on their face, it just makes you feel so good. Pretty much, people are really appreciative."

\section{B. Having a positive impact on others.}

The positive good feelings that come as a result of community service can also be very powerful and motivating for some youth. During a group discussion about contributing in the community, youth agreed that they feel valued when they have made a difference in someone's life by either helping them in some way or positively influencing them or changing their minds towards a bad behavior. One youth beamed that his community service was important to him because it actually made a difference in his father's life, "I think that whenever you get feedback from something that you did, it really makes you feel important, or you feel like you have done something. I did Rage Against the Haze (a youth movement against tobacco), and with me doing that, my dad stopped smoking. So, that was really important and youth empowering ... when I can influence people to do certain things."

Several youth concurred about participating in the community and working towards solving community problems, "I just get a really great feeling out of it. I mean, it just makes me feel good to know that I'm giving my time for other people instead of, you know, going shopping or something."

\section{Contributing to the success of their program.}

According to the youth, not only does community service have intrinsic benefits, so does engagement in program processes. Having an active role in a program makes youth feel valued even though they recognize there are things which only the adult leader can do. One female participant explained, "You want to feel like you really do have a part. I mean, you may not necessarily be able to lead it because the adults may know a lot more than you do. But, you still have an active part in it." One youth recalled how he was made to feel valued by the program leader. From his experience, the program leader would suggest goals but leave it up to the youth to determine how the project got accomplished as indicated by this statement, "This is what we want you to do. Now tell us how you want to do it." 
Volunteering in community service projects and participating in youth programs is often a choice for the youth. Therefore, the great feeling the youth get from helping others and contributing to the good of the program is the biggest reward and reason to continue participating. Additionally, one youth smiled and said, "volunteering can give you really good bragging rights to say 'I did that!"'

\section{Discussion}

Out-of-school community-based programs provide youth an alternative to their unstructured discretionary time during non-school hours. During unstructured or unsupervised time, youth may seek opportunities that are harmful to themselves or others. Alternatively, out-of-school community-based programs provide supervised places for youth to gather and host constructive activities in which youth can participate. While time spent participating in organized community program activities are hours not spent engaged in destructive behaviors, one's participation in these programs does not necessarily protect or discourage them from risk taking at another time. Therefore, the quality and meaningfulness of a youth's experience in a program are important for keeping youth participating and minimizing desire for risky behaviors.

The youth results indicate meaningfulness of participation in community-based programs is determined by a youth's opportunity for expression and to have a voice without censorship, occasions for exploring diversity and building social networks with youth and adults, the potential for contribution and being valued in the program. Therefore, community-based youth programs have a duty to provide those meaningful opportunities for youth, assisting their youth development and empowerment.

\section{What does this mean for community-based youth programs?}

\section{Program Philosophy,}

Our findings would suggest that a program should have a philosophy and climate that is entirely youth-focused to contribute to the meaningfulness of an experience. While it is essential for a program to be fun and social for youth, youth discovery and expression matter. Innovation can increase when a program seeks youth opinions and embraces the creativity and ingenuity of youth with youth-initiated/youth-led projects. Programs that support this idea may be flexible in their approaches to planning and program implementation.

Programs with a value for nurturing adult/youth relationships will assist a greater community appreciation for all that youth have to offer. This may lead to increased opportunities to foster youths' strength and potential both within the program and the community at large.

Additionally, programs that introduce youth participants to a variety of people enable them to break out of their normal peer group. Youth learn to communicate, interact, and work with others not like themselves; they broaden their scope and learn new perspectives; and they identify a network to accomplish goals.

Therefore, a community-based youth program with a youth oriented philosophy should value all youth and be inclusive, advocate for youth at all times, encourage and support youth ideas for projects and program improvements, provide constructive adult feedback, and reward youth for their initiative. 


\section{Program Procedures.}

Youth have something to gain or lose from community-based programs and should be considered stakeholders of the program and not just recipients of services. A program's organizational structure should allow youth to have an active role and voice in programmatic decision-making and program governance which contributes to the good of the program and/or community.

A program which is willing to have a philosophy of inclusion and is willing to recruit from different social demographics and diverse areas of a community has the potential of making a program stronger and more meaningful for the entire group. Therefore, membership recruitment practices or participant selection in program activities are instrumental to whether youth have opportunities to experience diversity

Youth programs can be opportunities for youth to "safely" network with others from various backgrounds. When possible, program goals should be broad enough to appeal to many youth. Programs offering social action or service missions may encourage a variety of participants to interact collectively as a team towards a common goal.

Programs should have reward mechanisms for validating and recognizing youth efforts Otherwise, programs are silently sustaining the negative stereotype that adolescents mostly engage in risk taking behaviors rather than productive activities.

Additionally, programs that offer opportunities for socializing and communication with friends and peers during the program meetings can help to foster new perspectives, build collective identity, and strengthen peer support as well as develop youth confidence in how they express themselves.

\section{Program Leader.}

The youth universally agreed that the program leader had a direct impact on their experiences in the program. Program leaders play an important role in limiting censorship of youth expression and for fostering youth contributions in youth programs. Program leaders should first acknowledge that youth have a voice. They should then be available to the youth as a willing audience and create a safe environment that is free of censorship. That is, youth should know that the program leader's primary interest is the youth participant and that they can approach the program leader with an idea. In turn, program leaders should be willing to hear all of their ideas, encourage youth to conceptualize and plan a program or challenge the youth to find a solution to a problem. Programs leaders who seek and embrace youth ideas and opinions and listen to their input stand the chance of gaining youth ownership of a problem which may result in group identity and increase the meaningfulness of their participation and goal attainment within the program.

Program leaders can also help youth have a more meaningful experience by letting youth be a part of the solution through decision-making. They can simply ask youth for changes they believe should be incorporated into their program's operation and structure. This involvement, as well as, program leaders who try to see things the way youth do, and adults who acknowledge youth processes, makes youth feel valued. While scrutiny of youth expression and voice is inevitable, program leaders should avoid flippant critique that may lead to youth insecurity and hesitancy when youth wish to express themselves. 
Therefore, adult leaders who create a safe place for youth to gather and express themselves productively will not only enhance a youth's level of enjoyment in a program but foster meaningful participation that will ultimately lead to a youth's development and empowerment. These leaders will ask for youth opinions and listen to their suggestions. They will facilitate youth ownership of the program by engaging them in program problem solving and allowing youth processes for achieving goals. These leaders will let youth fail and/or succeed and recognize their efforts either way. But most importantly, these leaders will have a positive youth outlook without being domineering, forceful or "constantly watchful."

\section{Conclusion}

Programs that engage youth in meaningful participation, as expressed by the youth and outlined above, are allowing their participants opportunities to develop competencies and skills for becoming productive members of society. To facilitate empowerment among adolescents is to provide a preventive intervention for many of the problems that confront this population. The level of program participation by a youth and the number of dimensions of meaningful participation employed may affect the empowerment outcome. The more active and engaged a youth is in a program and the more dimensions of meaningful participation employed, the more likely a positive benefit is to occur. The youth who choose to participate as passive recipients of youth program services are likely to benefit less.

\section{References}

Astroth, K.A. (1997). Havens of hope: Vibrant youth groups in the lives of today's young people. (Opinion Paper). Washington, D.C. U.S. Department of Education.

Bales, S.N. (2001). Reframing youth issues for public consideration and support. Washington, D.C. Frameworks Institute.

Chinman, M.J., \& Linney, J.A. (1998). Toward a model of adolescent empowerment: Theoretical and empirical evidence. The Journal of Primary Prevention, 18(4), 393-413.

George, M.A., Daniel, M., \& Green, L.W. (1999). Appraising and funding participatory research in health promotion. International Quarterly of Community Health Education, 18(2), 181-197.

Glaser, B.G., \& Strauss, A.L. (1967). The discovery of grounded theory: Strategies for Qualitative Research. Chicago: Aldine.

Hawkins, J.D., Catalano, R.F., \& Miller, J.Y. (1992). Risk and protective factors for alcohol and other drug problems in adolescence and early adulthood: Implications for substance abuse prevention. Psychological Bulletin, 112(1), 64-105.

Hawkins, W.E. (1998). Consequences and strategies for youth involvement. Children and Youth Services Review, 20(9/10), 753-755.

Kim, S., Crutchfield, C., Williams, C., \& Hepler, N. (1998). Toward a new paradigm in substance abuse and other problem behavior prevention for youth: Youth development and empowerment approach. Journal of Drug Education, 28(1), 1-17. 
Lerner, R.M., \& Galambos, N.L. (1998). Adolescent development: Challenges and opportunities for research, programs, and policies. Annual Review of Psychology, 49, 413-446.

Linquanti, R. (1992). Using community-wide collaboration to foster resiliency in kids: $A$ conceptual framework. Portland, OR: Western Regional Center for Drug-Fee Schools and Communities, Far West Laboratory for Eduational Research and Development.

Minkler, M., \& Wallerstein, N. (2003). Introduction to Community based participatory research. In M. Minkler and N. Wallerstein (Eds.), Community based participatory research for health (pp3-26). San Francisco: Jossey-Bass.

Oden, S. (1995). Studying youth programs to assess influences on youth development: New roles for researchers. Journal of Adolescent Research, 10(1), 173-186.

Royce, S.W., Parra-Medina, D., \& Messias, D. (2006). Using Photovoice to examine and initiate youth empowerment in community-based programs: A picture of process and lessons learned. Californian Journal of Health Promotion, 4(3), p. 80-91.

Stringer, E. (1999). Action Research (Vol. 2nd Edition). Thousand Oaks, CA: Sage.

Wang, C., \& Burris, M.A. (1997). Photovoice: Concept, methodology, and use for participatory needs assessment. Health Education and Behavior, 24(3), 369-387.

Zimmerman, M.A. (2000). Empowerment theory: Psychological, organizational and community levels of analysis. In J. Rappaport \& E. Seidman (Eds.), Handbook of Community Psychology (pp. 43-63). New York: Plenum Press.

Author notes. This research was supported by funding from the American Legacy Foundation with collaboration from the Centers for Disease Control Foundation and technical assistance from the Centers for Disease Control and Prevention. Its contents are solely the responsibility of the author and do not necessarily represent the official views of the American Legacy Foundation, the Centers for Disease Control Foundation, their respective staff or their respective Board of Directors.

(C) Copyright of Journal of Youth Development $\sim$ Bridging Research and Practice. Content may not be copied or emailed to multiple sites or posted to a listserv without copyright holder's express written permission. However, users may print, download or email articles for individual use. 